Int. J. Electrochem. Sci., 14 (2019) $10681-10692$

International Journal of

ELECTROCHEMICAL

SCIENCE

www.electrochemsci.org

\title{
PVC membrane and All-Solid-Sate Sensor for the Potentiometric Analysis of Trimipramine
}

\author{
Maryam Sharifi-Sistani ${ }^{1}$, Farnoush Faridbod ${ }^{2.3, *}$, Hamid Rashedi $^{1,4}$, Nazila Davarkhah $^{2}$ \\ ${ }^{1}$ Alborz Campus, University of Tehran, Tehran, Iran \\ ${ }^{2}$ Center of Excellence in Electrochemistry, Faculty of Chemistry, University of Tehran, Tehran, Iran \\ ${ }^{3}$ Biosensor Research Center, Endocrinology \& Metabolism Molecular-Cellular Sciences Institute, \\ Tehran University of Medical Sciences, Tehran, Iran \\ ${ }^{4}$ Department of Chemical Engineering, Faculty of Engineering, University of Tehran, Tehran, Iran \\ *E-mail: faridbodf@khayam.ut.ac.ir
}

doi: $10.20964 / 2019.11 .01$

Received: 5 August 2017 / Accepted: 16 September 2017 / Published: 7 October 2019

Two symmetrical and asymmetrical potentiometric membrane electrodes were developed and evaluated for the analysis Trimipramine (TMP). The symmetrical electrode was a poly(vinyl chloride) (PVC) membrane electrode (PME), a similar membrane of which was further used on an all-solid-state (ASS) electrode to make the asymmetrical ASS-PME. Both instruments function based on the ion-exchange between aqueous solutions of TMP and an organic phase (i.e. the PVC membrane) optimally composed of $6 \%$ of an ion-pair of TMP-TPB, $63 \%$ of dibutyl phthalate, $30 \%$ of PVC and $1 \%$ of NaTPB. The optimal electrodes revealed a Nernstian behavior. The ASS electrode was prepared using a conductive composite of graphite, MWCNTs, and epoxy resin which was coated on a copper wire. The ASS-PME, on the other hand, was prepared by covering the ASS electrode with a thin layer of the optimal PVC membrane. The PME and ASS-PME revealed Nernstian slopes of $57.1 \pm 0.3$ and $58.2 \pm 0.4 \mathrm{mV} / \mathrm{decade}$ over the concentration ranges of $1.0 \times 10^{-6}-1.0 \times 10^{-2}$ and $1.0 \times 10^{-7}-1.0 \times 10^{-4} \mathrm{M}$. The method of using the instruments was validated and the applicability of sensors for quality control analyses of TMP in pharmaceutical formulations, was also evaluated.

Keywords: Trimipramine, PVC membrane sensors, All solid state electrodes, Ion-pair complex

\section{FULL TEXT}

(C) 2019 The Authors. Published by ESG (www.electrochemsci.org). This article is an open access article distributed under the terms and conditions of the Creative Commons Attribution license (http://creativecommons.org/licenses/by/4.0/). 